\title{
Intracellular Calcium and Ventricular Function \\ Effects of Nisoldipine on Global Ischemia in the Isovolumic, Coronary-Perfused Heart
}

Ivo Amende, Lisa A. Bentivegna, Adib J. Zeind, Paul Wenzlaff, William Grossman, and James P. Morgan

The Charles A. Dana Research Institute and Harvard-Thorndike Laboratory, the Department of Medicine (Cardiovascular Division), Beth Israel Hospital and Harvard Medical School, Massachusetts 02215

\begin{abstract}
Ischemia-induced ventricular dysfunction has been shown to be associated with increased diastolic and systolic intracellular concentrations of free, ionized calcium $\left(\left[\mathrm{Ca}^{2+}\right]_{1}\right)$. The present study was designed to determine the effects of the $\mathrm{Ca}^{2+}$ antagonist nisoldipine on the relationship between $\left[\mathrm{Ca}^{2+}\right]_{i}$ and left ventricular contraction and relaxation during ischemia and reperfusion on a beat-to-beat basis. Nine isovolumic coronary-perfused ferret hearts were made globally ischemic for $3 \mathrm{~min}$ and reperfused for $10 \mathrm{~min}$. Ischemia and reperfusion were repeated during perfusion with a buffer containing $10^{-8} \mathrm{M}$ nisoldipine. From left ventricular developed pressure, time to peak pressure and time to $50 \%$ pressure decline were obtained. $\left[\mathrm{Ca}^{2+}\right]_{\text {h }}$ was determined with the bioluminescent protein aequorin.

Global ischemia caused a rapid decline in contractile function and a significant increase in diastolic $\left[\mathrm{Ca}^{2+}\right]_{\text {, }}$, from 0.35 to $0.81 \mu \mathrm{M}$, and in systolic $\left[\mathrm{Ca}^{2+}\right]_{i}$, from 0.61 to $0.96 \mu \mathrm{M}$. During reperfusion, $\left[\mathrm{Ca}^{2+}\right]$ returned to baseline while ventricular function was still impaired. Relaxation was more affected than systolic contractile function.

Nisoldipine significantly reduced the ischemia-induced rise in diastolic $\left[\mathrm{Ca}^{2+}\right]$ to $0.62 \mu \mathrm{M}$, and in systolic $\left[\mathrm{Ca}^{2+}\right]$, to 0.77 $\mu \mathrm{M}$, and lessened the decrease in contractile function. Nisoldipine significantly accelerated the decline in $\left[\mathrm{Ca}^{2+}\right]_{\mathrm{i}}$ during reperfusion and improved recovery of contractility and relaxation. These effects were associated with a significant diminution in ischemic lactate production. Taken together, our results provide direct quantitative evidence on a beat-to-beat basis that the calcium antagonist nisoldipine can ameliorate ischemia-induced abnormalities in $\left[\mathrm{Ca}^{2+}\right]_{1}$ handling, an effect that was associated with improved myocardial function during early reperfusion. (J. Clin. Invest. 1992. 89:2060-2065.) Key words: calcium - aequorin • contractile function • relaxation • ischemic myocardium • calcium antagonist
\end{abstract}

This work was presented in part at the 40th Scientific Session of the American College of Cardiology, Atlanta, Georgia, in 1991.

Address reprint requests to Dr. J.P. Morgan, Beth Israel Hospital, 330 Brookline Ave., Boston, MA 02215. I. Amende's and P. Wenzlaff's present address is Department of Cardiology, Medical University, 300 Hannover 61, Germany.

Received for publication 15 April 1991 and in revised form 31 January 1992.

J. Clin. Invest.

(c) The American Society for Clinical Investigation, Inc.

0021-9738/92/06/2060/06 \$2.00

Volume 89, June 1992, 2060-2065

\section{Introduction}

Acute global ischemia causes a rapid increase in intracellular calcium $\left(\left[\mathrm{Ca}^{2+}\right]_{\mathrm{i}}\right)$ associated with impaired ventricular function $(1,2)$. The ischemia-induced mechanical dysfunction has been related to a decrease in the responsiveness of the myofilaments to $\left[\mathrm{Ca}^{2+}\right]_{\mathrm{i}}(2,3)$. Experimental studies have shown that $\mathrm{Ca}^{2+}$ antagonists protect the myocardium against some of the mechanical and metabolic consequences of acute ischemia (4-6). It has recently been shown that verapamil and diltiazem attenuate the increase in $\left[\mathrm{Ca}^{2+}\right]_{i}$ during ischemia $(1,7)$. Little is known about the effects of $\mathrm{Ca}^{2+}$ antagonists on the relationship between ischemia-induced abnormalities in $\left[\mathrm{Ca}^{2+}\right]_{\mathrm{i}}$ and myocardial function in the intact heart on a beat-to-beat basis.

Measurements of $\left[\mathrm{Ca}^{2+}\right]_{i}$ during ischemia in ferret hearts loaded with the bioluminescent $\left[\mathrm{Ca}^{2+}\right]_{i}$ indicator aequorin have shown a very rapid increase in diastolic and systolic $\left[\mathrm{Ca}^{2+}\right]_{\mathrm{i}}$ that gradually returned to baseline during reperfusion (2). We have used this experimental model to determine the effects of the "second generation" $\mathrm{Ca}^{2+}$ antagonist nisoldipine, a 1,4-dihydropyridine derivative, on $\left[\mathrm{Ca}^{2+}\right]_{\mathrm{i}}$ handling and left ventricular function during brief periods of ischemia and reperfusion.

\section{Methods}

The experimental preparation has been previously described in detail (2). Nine male ferrets 10-14 wk old were anesthetized and heparinized. The hearts were removed and Langendorff-perfused with a modified Krebs-Henseleit solution composed of $(\mathrm{mM}): \mathrm{NaCl} 118, \mathrm{KCl} 4.7$, $\mathrm{MgCl}_{2} 1.2, \mathrm{CaCl}_{2} 2, \mathrm{KH}_{2} \mathrm{PO}_{4} 1.2, \mathrm{NaHCO}_{3} 23$, and dextrose 5.5. The solution was saturated with $95 \% \mathrm{O}_{2} / 5 \% \mathrm{CO}_{2}$ to adjust the $\mathrm{pH}$ to 7.4 . Perfusion flow was set to achieve a pressure of $80 \mathrm{mmHg}$ measured with a transducer (model P23Db; Gould-Statham, Cleveland, $\mathrm{OH}$ ). A thin latex balloon tied to the end of a polyethylene tube was inserted into the left ventricle (LV) ${ }^{1}$ through the mitral valve and connected to the transducer to measure isovolumic pressure. The balloon volume was set to achieve an end-diastolic pressure of $8-15 \mathrm{mmHg}$. Thebesian venous return was drained from the LV via a tube placed in parallel with the LV catheter. The pulmonary artery was cannulated and drained. Each heart was paced at $1.7-2.0 \mathrm{~Hz}$ via a platinum wire inserted into the right ventricle through the right atrium.

In the present study, we applied our macroinjection method to the isolated, perfused whole heart preparation, as previously described in detail (2). After a 20-min stabilization period, the coronary perfusate was replaced with a low $\mathrm{Ca}^{2+}$ solution composed of (mM): $\mathrm{NaCl} 118$, $\mathrm{KCl} 4.7, \mathrm{KH}_{2} \mathrm{PO}_{4} 1.2, \mathrm{MgCl}_{2} 5, \mathrm{NaHCO}_{3} 23$, dextrose 20 , and pyruvate

1. Abbreviations used in this paper: LV, left ventricle; NMR, nuclear magnetic resonance. 
5. The $\mathrm{pH}$ was $7.30 \pm 0.02$ when saturated by a gaseous mixture of $95 \%$ $\mathrm{O}_{2} / 5 \% \mathrm{CO}_{2}$ at $20^{\circ} \mathrm{C}$. Within $3 \mathrm{~min}$, the heart became completely quiescent and coronary resistance fell. The coronary perfusion rate was then reduced to $5-8 \mathrm{ml} / \mathrm{min}$ for maintenance of a perfusion pressure of $25-30 \mathrm{mmHg}$. Subsequently, the heart was temporarily raised out of the organ bath, and an aequorin-loading solution composed of aequorin $1.0 \mathrm{mg} / \mathrm{ml}, \mathrm{NaCl} 154 \mathrm{mM}, \mathrm{KCl} 5.4 \mathrm{mM}, \mathrm{MgCl}_{2} 1.0 \mathrm{mM}$, Hepes

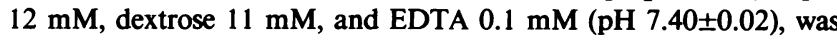
injected into the interstitium of the epicardium, just beneath the epimysium, with a low-resistance glass micropipette. In toto, 3-5 $\mu \mathrm{l}$ of the aequorin-loading solution was injected within $3 \mathrm{~min}$ into a localized region of $\sim 3 \mathrm{~mm}$ in diam. After loading, the heart was repositioned in the concavity at the bottom of the organ bath and the aequorin-loaded region of the LV was directed toward the cathode of the photomultiplier tube. The $\mathrm{Ca}^{2+}$ concentration of the coronary perfusate was slowly increased in a stepwise fashion every $15 \mathrm{~min}$ over the period of $1 \mathrm{~h}$ to prevent calcium paradox. When the $\mathrm{Ca}^{2+}$ concentration in the perfusate reached $0.3 \mathrm{mM}$, the perfusion rate and the temperature were gradually increased over the course of $15 \mathrm{~min}$ to attain the levels present before loading. During this period, the heart showed an initiation of weak and sporadic contractions. After replacement of coronary perfusate by the standard solution at the previous perfusion rate at $30^{\circ} \mathrm{C}$, the $\mathrm{LV}$ isovolumic pressure and coronary perfusion pressure recovered within $3 \mathrm{~min}$, and a steady state was achieved within $20 \mathrm{~min}$.

After aequorin loading and stabilization, the hearts were perfused with a non-recirculating buffer solution that passed through them only once before discard. The aequorin light signal, $\mathrm{LV}$ isovolumic pressure, and coronary perfusion pressure were recorded simultaneously on a strip chart recorder (Gould Inc. Instruments Div., Cleveland, $\mathrm{OH}$ ) and magnetic tape recorder (Vetter, Petersburg, PA). Quantitation of calcium was performed in six of the studied hearts by the method of fractional luminescence (8). In brief, this involves: $(a)$ normalization of the aequorin light at each phase of the experiment by the amount of active aequorin in the preparation; and $(b)$ conversion of the normalized light signal to a $\left[\mathrm{Ca}^{2+}\right]_{i}$ value by use of an in vitro calibration curve (2).

Nisoldipine (gift of Dr. Alexander Scriabine, Miles Inc., West Haven, CT) was dissolved in polyethylene glycol 400 (PEG400) to produce a $2.58 \times 10^{-3} \mathrm{M}$ stock solution. Nisoldipine was added to the perfusion buffer to achieve a final concentration of $10^{-8} \mathrm{M}$. Previous studies have demonstrated that higher concentrations of the vehicle (PEG400) have no effect on cardiac function, high energy metabolites, or recovery from ischemia (9). As a result of nisoldipine's light sensitivity, the perfusion lines were covered with an opaque wrapping.

After control perfusion, the hearts were made globally ischemic for 3 min by clamping the perfusion line, and were then reperfused for 10 min. After 20 min of perfusion with a buffer solution containing nisoldipine $10^{-8} \mathrm{M}$, global ischemia was repeated for $3 \mathrm{~min}$, followed by 10 min of reperfusion. LV end-diastolic pressure, developed pressure (peak systolic pressure minus end-diastolic pressure), time to peak pressure, and time to $50 \%$ pressure decline were measured from LV pressure recordings. End-diastolic and end-systolic $\left[\mathrm{Ca}^{2+}\right]_{i}$ were determined from the aequorin light signal. Lactate production was measured in samples taken via the right ventricular drainage during $1 \mathrm{~min}$ before ischemia and during the first minute of reperfusion (Roche Analytical Instruments Inc., Nutley, NJ).

Observations before and after nisoldipine administration were compared statistically using analysis of variance. When an overall significance was observed, multiple comparisons were performed to determine which paired comparisons were significant. A value of $P$ $<0.05$ was considered significant. Data are expressed as mean \pm SD.

\section{Results}

Fig. 1 and Table I show the effects of ischemia and reperfusion in our preparations before and after the administration of nisoldipine. Before administration of the drug, ischemia caused a rapid fall in LV developed pressure by $94 \%$ in the third minute. With reflow, LV developed pressure returned to near preischemic control values after $10 \mathrm{~min}$. Time to peak pressure decreased during ischemia and remained prolonged by $11 \%$ for 4 min with subsequent return to control values. During $3 \mathrm{~min}$ of ischemia, time to $50 \%$ pressure decline followed a time course that resembled time to peak pressure. After $1 \mathrm{~min}$ of reflow, however, time to $50 \%$ pressure decline was substantially prolonged by $57 \%$, gradually returning to near control values.

Perfusion with buffer containing nisoldipine $10^{-8} \mathrm{M}$ caused a significant decrease in LV developed pressure, from 101 to 79 $\mathrm{mmHg}$, and an increase in $\mathrm{LV}$ end-diastolic pressure, from 10 to $16 \mathrm{mmHg}$, with a further rise to $18 \mathrm{mmHg} 10 \mathrm{~min}$ after reperfusion. Nisoldipine significantly reduced systolic $\left[\mathrm{Ca}^{2+}\right]_{\mathrm{i}}$ from 0.59 to $0.55 \mu \mathrm{M}$. Diastolic $\left[\mathrm{Ca}^{2+}\right]_{\mathrm{i}}$ remained unchanged.

Nisoldipine moderately lessened the decrease in LV developed pressure during ischemia and improved early recovery with reflow, as shown by the absolute values and percent change from preischemic values in Fig. 1 and Table I. Nisoldipine had no effects on time to peak pressure during ischemia and recovery following reperfusion, but significantly improved isovolumic relaxation during the early recovery period.

Ischemia caused an immediate increase in diastolic $\left[\mathrm{Ca}^{2+}\right]_{\mathrm{i}}$ from $0.35 \mu \mathrm{M}$ to $0.81 \mu \mathrm{M}$ after $3 \mathrm{~min}$ (Table I). During reperfusion, diastolic $\left[\mathrm{Ca}^{2+}\right]_{\mathrm{i}}$ stayed elevated until $4 \mathrm{~min}$. Nisoldipine delayed the rise in diastolic $\left[\mathrm{Ca}^{2+}\right]_{\mathrm{i}}$ and reduced its extent at 3 min of ischemia. After $1 \mathrm{~min}$ of reflow, $\left[\mathrm{Ca}^{2+}\right]_{\mathrm{i}}$ returned to baseline values. Systolic $\left[\mathrm{Ca}^{2+}\right]_{\mathrm{i}}$ showed a similar time course during ischemia and reperfusion to that of diastolic. $\left[\mathrm{Ca}^{2+}\right]_{i}$ before and after nisoldipine. During ischemia under control conditions, lactate rose from $0.6 \pm 0.4$ to $6.4 \pm 2.3 \mathrm{mg} / \mathrm{dl}$, and nisoldipine significantly attenuated this increase by more than $50 \%$ $(0.4 \pm 0.4$ to $3.0 \pm 1.5 \mathrm{mg} / \mathrm{dl})$.

\section{Discussion}

Limitations of methods. The sensitivity and reliability of the aequorin technique as a method for determining diastolic and systolic $\left[\mathrm{Ca}^{2+}\right]_{i}$ have been validated $(2,10)$. But continuous determination of $\left[\mathrm{Ca}^{2+}\right]_{\mathrm{i}}$ by this technique including two periods of ischemia is subject to error because of aequorin consumption (11). Accordingly, a correction must be applied to account for the resultant loss in light (2), as in this investigation.

The interaction of aequorin with $\left[\mathrm{Ca}^{2+}\right]_{\mathrm{i}}$ is competitively inhibited by $\mathrm{Mg}^{2+}$ ions (8). Extended periods of ischemia are associated with an increase in intracellular $\mathrm{Mg}^{2+}\left(\left[\mathrm{Mg}^{2+}\right]_{\mathrm{i}}\right)$ that is directly related to the decrease in intracellular ATP (12). The method used to quantitate $\left[\mathrm{Ca}^{2+}\right]_{\mathrm{i}}$ in the present study assumes a constant $\left[\mathrm{Mg}^{2+}\right]_{i}$ concentration. Therefore, periods of global ischemia were restricted to $3 \mathrm{~min}$ to avoid significant changes in $\operatorname{ATP}(3,7)$.

In the present study, repetitive periods of ischemia were used to determine the effects of nisoldipine on ischemic myocardium. The effects of the drug could mask delayed recovery after the control ischemic period. A previous study has shown that the mechanical changes and the amount of lactate production were virtually identical during two 3-min episodes of global ischemia followed by a 23 -min recovery period (13). We have found that brief, repeated periods of ischemia as employed in the present experiments produce reproducible 
A

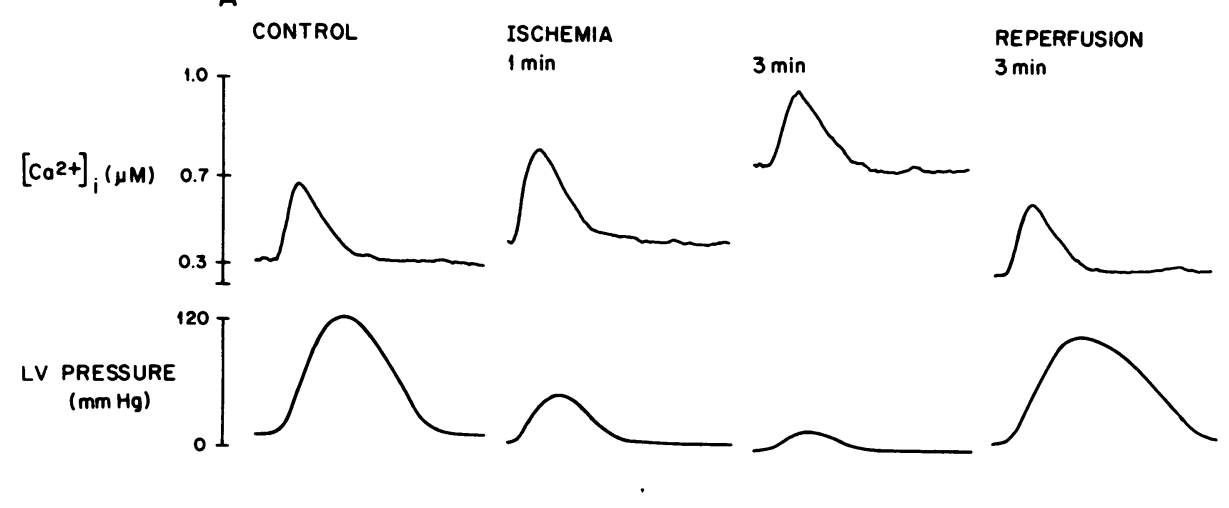

$10^{-8} \mathrm{M}$ NISOLDIPINE

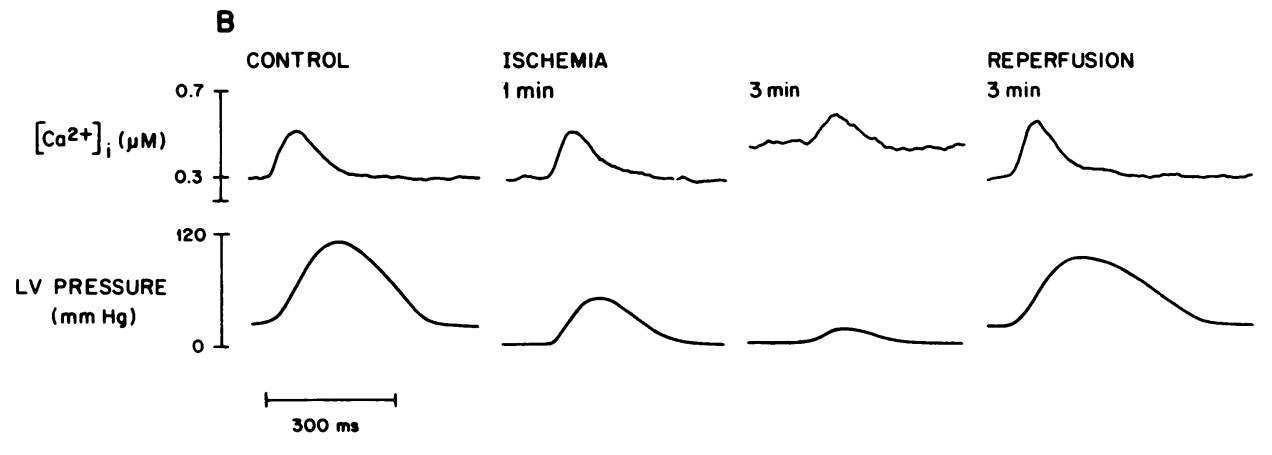

Figure 1. Effects of ischemia on individual $\left[\mathrm{Ca}^{2+}\right]_{\mathrm{i}}$ transients and isovolumic left ventricular $(\mathrm{LV})$ pressure in control, after 1 and 3 min of ischemia and $3 \mathrm{~min}$ after reperfusion; $(A)$ before $(B)$ during perfusion with buffer containing $10^{-8} \mathrm{M}$ nisoldipine. changes in $\left[\mathrm{Ca}^{2+}\right]_{\mathrm{i}}$ (data not shown). It is conceivable, however, that preconditioning effects caused by the control ischemic period may obscure effects of nisoldipine on $\left[\mathrm{Ca}^{2+}\right]_{\mathrm{i}}$ during the subsequent ischemic episode. Because nisoldipine washes out poorly, it was not possible to test the reversibility of the drug's effect in our preparations.

Effects of nisoldipine on LV function. The most important result of our study is that it provides direct quantitative evidence, on a beat-to-beat basis, that the calcium antagonist nisoldipine can ameliorate ischemia-induced abnormalities in $\left[\mathrm{Ca}^{2+}\right]_{\mathrm{i}}$ handling, an effect that correlates with improved myocardial function during early reperfusion. The results of our study concerning the effects of short periods of global ischemia followed by reperfusion on LV isovolumic pressure development and indices of relaxation are similar to those previously reported (13). Moreover, our results indicate a relatively greater effect of ischemia on the rate of isovolumic relaxation than developed pressure generation during the recovery period $(13,14)$.

Previous studies have suggested that calcium antagonists modify the functional changes that occur with ischemia and reperfusion. Watts et al. (6) reported that verapamil $\left(7.5 \times 10^{-8}\right.$ M-2 $\times 10^{-6} \mathrm{M}$ ) improves the functional recovery and enhances ATP production of rat hearts subjected to $27 \mathrm{~min}$ of global ischemia followed by $30 \mathrm{~min}$ of reperfusion. The same investigators reported similar beneficial effects of nifedipine $\left(7.5 \times 10^{-7} \mathrm{M}\right)$ and diltiazem $\left(7.5 \times 10^{-6} \mathrm{M}\right)$ in a related study (11). So-called "second generation" calcium blockers such as nisoldipine are thought to have more effective vasodilator action and less negative inotropic effects than drugs such as nifedipine and verapamil (15). Few studies of nisoldipine's effects on myocardial function, however, have been reported. de Jong et al. (16) reported that nisoldipine (1-300 $\mathrm{nM}$ ) prevented ATP breakdown and improved coronary flow during $15 \mathrm{~min}$ of global ischemia in rats. The same investigators subsequently found that nisoldipine $30 \mathrm{nM}$ decreased glucose utilization and lactate production during $15 \mathrm{~min}$ of global ischemia (17). These beneficial effects of nisoldipine may occur in concentrations as low as $1 \mathrm{nM}$. Watts et al. (18) reported that this low concentration of nisoldipine had minimal effects on the functional performance of rat hearts, but significantly enhanced recovery of function after global ischemia. The dose of nisoldipine used in our experiments $\left(10^{-8} \mathrm{M}\right)$ produced a $27 \%$ decrease in peak developed pressure, a result similar to that reported by de Jong et al. (16). Therefore, the beneficial actions of nisoldipine probably occur through a combination of two main effects: (a) the blockade of voltage-dependent $\mathrm{Ca}^{2+}$ channels in the sarcolemma reduces trigger $\left[\mathrm{Ca}^{2+}\right]_{i}$ current and the beat-to-beat release of $\mathrm{Ca}^{2+}$, consequently producing a negative inotropic effect; and $(b)$ the energy-sparing effect of this reduction in $\left[\mathrm{Ca}^{2+}\right]_{\mathrm{i}}$, which lessens the need for ATP expenditure during basal excitation-contraction coupling, and consequently increases the intracellular stores of high energy phosphates available to the myocyte during early ischemia. Enhanced ATP availability would be expected to help preserve systolic and diastolic function, the latter requiring considerable energy expenditure (19). The greater energy dependence of diastole versus systole may also explain the relatively greater effect of ischemia on the parameters of relaxation.

A limited number of reports have appeared in the literature concerning the effects of calcium antagonists on relaxation parameters during global ischemia and reperfusion. Nifedipine 
Table I. Effects of Nisoldipine on $\left[\mathrm{Ca}^{2+}\right]_{i}$ and LV Function during Ischemia and Reperfusion

\begin{tabular}{|c|c|c|c|c|c|c|c|c|c|c|c|}
\hline \multirow[b]{2}{*}{ Min } & \multicolumn{4}{|c|}{ Ischemia } & \multicolumn{7}{|c|}{ Reperfusion } \\
\hline & 0 & 1 & 2 & 3 & 1 & 2 & 3 & 4 & 5 & 6 & 10 \\
\hline \multirow[t]{2}{*}{ LVP (mm Hg) } & 108.7 & $37.7^{*}$ & $16.9^{*}$ & $6.9^{*}$ & 73.4* & 83.9* & $90.3^{*}$ & $95.3^{*}$ & $97.8^{*}$ & $98.8^{*}$ & $100.3^{*}$ \\
\hline & \pm 15.7 & \pm 7.4 & \pm 3.8 & \pm 3.8 & \pm 18.9 & \pm 16.9 & \pm 19.6 & \pm 17.8 & 17.0 & \pm 16.1 & \pm 15.6 \\
\hline \multirow[t]{2}{*}{$\%$ change } & & $65.1^{*}$ & $-84.3^{*}$ & $-93.6^{*}$ & $-33.0^{*}$ & $-23.1^{*}$ & $-17.6^{*}$ & $-12.6^{*}$ & $-10.4^{*}$ & $-9.3^{*}$ & $-7.3^{*}$ \\
\hline & & \pm 5.4 & \pm 3.2 & \pm 3.1 & \pm 11.1 & \pm 10.3 & \pm 10.2 & \pm 7.2 & \pm 5.8 & \pm 4.0 & \pm 3.6 \\
\hline$n$ & 9 & & & & & & & & & & 7 \\
\hline \multirow[t]{2}{*}{ LVEDP (mmHg) } & 10.0 & $2.8^{*}$ & $2.4^{*}$ & $2.3^{*}$ & 9.6 & 7.8 & 7.1 & 6.9 & 7.2 & 8.1 & 9.0 \\
\hline & \pm 4.2 & \pm 2.0 & \pm 2.4 & \pm 2.3 & \pm 5.1 & \pm 4.6 & \pm 4.2 & \pm 4.1 & \pm 4.5 & \pm 4.5 & \pm 5.9 \\
\hline \multirow[t]{2}{*}{$\%$ change } & & $-71.6^{*}$ & $-74.3^{*}$ & $-75.1^{*}$ & -2.9 & -16.6 & -24.1 & $-26.9^{*}$ & $-24.8^{*}$ & -16.7 & -9.4 \\
\hline & & \pm 25.2 & \pm 27.6 & \pm 27.9 & \pm 28.4 & \pm 38.1 & \pm 31.6 & \pm 27.6 & \pm 26.0 & \pm 22.9 & \pm 21.6 \\
\hline & 9 & & & & & & & & & & 7 \\
\hline \multirow{2}{*}{$\mathrm{TPP}(\mathrm{ms})$} & 159.9 & $119.6^{*}$ & $116.3^{*}$ & $116.9^{*}$ & $177.4^{*}$ & $177.3^{*}$ & $177.2^{*}$ & $177.1^{*}$ & $172.8^{*}$ & $169.6^{*}$ & 168.7 \\
\hline & \pm 7.5 & \pm 13.4 & \pm 11.9 & \pm 14.5 & \pm 19.8 & \pm 17.1 & \pm 16.4 & \pm 11.0 & \pm 12.2 & \pm 8.0 & \pm 7.9 \\
\hline \multirow[t]{2}{*}{$\%$ change } & & $-25.3^{*}$ & $-27.2^{*}$ & $-26.7^{*}$ & $+10.9^{*}$ & $+10.8^{*}$ & $+10.9^{*}$ & $+10.8^{*}$ & $+8.1^{*}$ & $+6.1^{*}$ & +4.2 \\
\hline & & \pm 7.3 & \pm 7.0 & \pm 11.1 & \pm 9.9 & \pm 8.2 & 7.0 & \pm 3.1 & \pm 3.6 & \pm 2.4 & \pm 4.2 \\
\hline \multirow{3}{*}{$\begin{array}{c}n \\
\mathrm{~T}_{508 x} \mathrm{P}(\mathrm{ms})\end{array}$} & 9 & & & & & & & & & & 6 \\
\hline & 137.1 & $88.3^{*}$ & $85.4^{*}$ & 83.3* & $215.2^{*}$ & $203.9^{*}$ & $188.8^{*}$ & $174.3^{*}$ & $163.0^{*}$ & $153.6^{*}$ & $145.2^{*}$ \\
\hline & \pm 10.0 & \pm 10.0 & \pm 15.0 & \pm 15.1 & \pm 20.1 & \pm 17.7 & \pm 15.1 & \pm 16.3 & \pm 17.8 & \pm 18.0 & \pm 12.7 \\
\hline \multirow{2}{*}{$\%$ change } & & $-35.9 *$ & $-38.0^{*}$ & $-39.4^{*}$ & $+57.3^{*}$ & $+48.8^{*}$ & $+38.1^{*}$ & $+27.2^{*}$ & $+18.9^{*}$ & $+11.9^{*}$ & +3.2 \\
\hline & & \pm 3.9 & \pm 7.3 & \pm 8.7 & \pm 15.0 & \pm 10.8 & \pm 9.3 & \pm 6.9 & \pm 6.5 & \pm 6.9 & \pm 2.9 \\
\hline$n$ & 9 & & & & & & & & & & 6 \\
\hline Diastolic & & & & & & & & & & & \\
\hline$\left[\mathrm{Ca}^{2+}\right]_{\mathrm{i}}(\mu \mathrm{M})$ & 0.35 & $0.54^{*}$ & $0.76^{*}$ & $0.81^{*}$ & $0.46^{*}$ & $0.44^{*}$ & $0.40^{*}$ & $0.38^{*}$ & 0.38 & 0.36 & 0.35 \\
\hline & \pm 0.03 & \pm 0.14 & \pm 0.11 & \pm 0.20 & \pm 0.06 & \pm 0.03 & \pm 0.03 & \pm 0.04 & \pm 0.03 & \pm 0.04 & \pm 0.04 \\
\hline$\%$ change & & $+55.2^{*}$ & $+116.5^{*}$ & $+133.0^{*}$ & $+32.0^{*}$ & $+25.8^{*}$ & $+16.0^{*}$ & $+8.8^{*}$ & +9.3 & +1.5 & +1.0 \\
\hline & & \pm 35.6 & \pm 31.4 & \pm 63.3 & \pm 15.8 & \pm 13.5 & \pm 11.8 & \pm 6.9 & \pm 10.8 & \pm 3.1 & \pm 3.6 \\
\hline$n$ & 6 & & & & & & & & & & \\
\hline Systolic & & & & & & & & & & & \\
\hline$\left[\mathrm{Ca}^{2+}\right]_{\mathrm{i}}(\mu \mathrm{M})$ & 0.61 & $0.77^{*}$ & $0.92^{*}$ & $0.96^{*}$ & $0.70^{*}$ & $0.69^{*}$ & $0.66^{*}$ & $0.63^{*}$ & 0.61 & 0.60 & 0.59 \\
\hline & \pm 0.04 & \pm 0.10 & \pm 0.10 & \pm 0.16 & \pm 0.05 & \pm 0.04 & \pm 0.05 & \pm 0.05 & \pm 0.04 & \pm 0.04 & \pm 0.05 \\
\hline$\%$ change & & $+27.7^{*}$ & $+52.7^{*}$ & $+60.0^{*}$ & $+15.2^{*}$ & $+13.0^{*}$ & $+8.5^{*}$ & $+4.3^{*}$ & +0.3 & -0.8 & -2.8 \\
\hline & & \pm 18.3 & \pm 20.1 & \pm 31.8 & \pm 4.7 & \pm 2.5 & \pm 1.5 & \pm 3.4 & \pm 0.8 & \pm 2.0 & \pm 2.5 \\
\hline$n$ & 6 & & & & & & & & & & \\
\hline & & & & & ${ }^{-8}$ M Nisold & & & & & & \\
\hline LVP (mmHg) & $79.3^{\ddagger}$ & $37.0^{*}$ & $20.9^{* \pm}$ & $9.8^{* \pm}$ & $61.0^{* \pm}$ & $68.2^{* *}$ & $70.3^{* \pm}$ & $71.0^{* \pm}$ & $72.0^{* *}$ & $71.4^{* \pm}$ & $68.8^{* 4}$ \\
\hline & \pm 13.1 & \pm 7.6 & \pm 6.9 & \pm 5.0 & \pm 15.2 & \pm 14.8 & \pm 15.4 & \pm 14.9 & \pm 15.0 & \pm 15.9 & \pm 18.2 \\
\hline$\%$ change & & $-53.0^{* *}$ & $-73.3^{* *}$ & $-87.3^{* t}$ & $-24.0^{* *}$ & $-14.7^{\ddagger}$ & $-12.1^{* 4}$ & $-11.1^{*}$ & $-9.9^{*}$ & $-10.6^{*}$ & $-12.7^{* \neq}$ \\
\hline & & \pm 7.2 & \pm 7.7 & \pm 5.9 & \pm 9.6 & \pm 7.8 & \pm 8.6 & \pm 8.2 & \pm 8.2 & \pm 8.7 & \pm 9.3 \\
\hline$n$ & 9 & & & & & & & & & 8 & 6 \\
\hline LVEDP (mmHg) & $16.2^{\ddagger}$ & $3.6^{*}$ & $2.9^{*}$ & $2.8^{*}$ & 14.1 & 12.1 & $13.0^{*}$ & $13.4^{\ddagger}$ & $14.1^{\ddagger}$ & $15.1^{\ddagger}$ & $18.2^{\ddagger}$ \\
\hline & \pm 9.0 & \pm 2.2 & \pm 2.5 & \pm 2.4 & \pm 10.4 & \pm 7.2 & \pm 9.3 & \pm 9.5 & \pm 9.6 & \pm 10.8 & \pm 12.7 \\
\hline$\%$ change & & -75.7 & -78.9 & -79.2 & $-15.4^{*}$ & $-22.1^{*}$ & $-18.4^{*}$ & $-17.3^{*}$ & $-14.0^{*}$ & -9.1 & +6.1 \\
\hline & & \pm 21.6 & \pm 23.7 & \pm 23.8 & \pm 20.7 & \pm 18.4 & \pm 25.0 & \pm 20.9 & \pm 17.1 & \pm 17.0 & \pm 22.7 \\
\hline$n$ & 9 & & & & & & & & & 8 & 7 \\
\hline TPP (ms) & 166.8 & $123.7^{*}$ & $112.9^{*}$ & $110.7^{*}$ & $184.2^{*}$ & $184.4^{*}$ & $184.0^{*}$ & $181.9^{*}$ & $178.8^{*}$ & $174.0^{*}$ & 173.2 \\
\hline & \pm 8.1 & \pm 10.3 & \pm 11.0 & \pm 11.7 & \pm 16.9 & \pm 15.5 & \pm 12.8 & \pm 8.3 & \pm 9.1 & \pm 10.1 & \pm 8.6 \\
\hline$\%$ change & & $-25.9^{*}$ & $-32.3^{*}$ & $-33.9^{*}$ & $+10.7^{*}$ & $+10.8^{*}$ & $+10.3^{*}$ & $+9.2^{*}$ & $+7.2^{*}$ & $+4.3^{*}$ & +2.0 \\
\hline & & \pm 5.9 & \pm 5.3 & \pm 5.4 & \pm 10.8 & \pm 9.1 & \pm 6.7 & \pm 4.7 & \pm 4.0 & \pm 3.5 & \pm 4.7 \\
\hline$n$ & 9 & & & & & & & & & 7 & 5 \\
\hline $\mathrm{T}_{50 \%} \mathrm{P}(\mathrm{ms})$ & 137.4 & $91.3^{*}$ & $82.4^{*}$ & $78.3^{*}$ & $200.0^{* *}$ & $193.6^{* \neq}$ & $179.7^{* \pm}$ & $166.8^{*}$ & $156.2^{*}$ & $151.6^{*}$ & 143.0 \\
\hline & \pm 11.5 & \pm 8.9 & \pm 10.0 & \pm 13.2 & \pm 18.3 & \pm 17.8 & \pm 15.5 & \pm 13.3 & \pm 16.5 & \pm 13.6 & \pm 12.1 \\
\hline$\%$ change & & $-33.6^{*}$ & $-40.0^{*}$ & $-43.2^{*}$ & $+45.6^{* *}$ & $+41.0^{* *}$ & $+31.0^{* *}$ & $+21.6^{*}$ & $+13.8^{*}$ & $+9.1^{*}$ & +0.6 \\
\hline & & \pm 5.9 & \pm 5.7 & \pm 7.2 & \pm 9.1 & \pm 7.4 & \pm 7.3 & \pm 4.3 & \pm 6.2 & \pm 5.0 & \pm 1.3 \\
\hline$n$ & 9 & & & & & & & & & 7 & 5 \\
\hline Diastolic & 0.35 & 0.43 & $0.53^{* \ddagger}$ & $0.62^{* *}$ & $0.40^{\ddagger}$ & $0.37^{\ddagger}$ & $0.35^{\ddagger}$ & $0.35^{\ddagger}$ & 0.35 & 0.35 & 0.36 \\
\hline$\left[\mathrm{Ca}^{2+}\right] \mathrm{i}(\mu \mathrm{M})$ & \pm 0.04 & \pm 0.11 & \pm 0.14 & \pm 0.14 & \pm 0.08 & \pm 0.03 & \pm 0.03 & \pm 0.04 & \pm 0.04 & \pm 0.04 & \pm 0.01 \\
\hline$\%$ change & & +24.0 & $+53.2^{* \pm}$ & $+78.8^{* *}$ & $\pm 14.2^{\ddagger}$ & $+6.5^{\ddagger}$ & $+1.7^{\ddagger}$ & $0^{ \pm}$ & 0 & 0 & +3.3 \\
\hline & & \pm 23.5 & \pm 29.1 & \pm 28.0 & \pm 17.2 & \pm 10.9 & \pm 4.1 & 0 & 0 & 0 & \pm 2.5 \\
\hline$n$ & 6 & & & & & & & & & 5 & 4 \\
\hline Systolic & $0.55^{\ddagger}$ & $0.63^{\ddagger}$ & $0.70^{* *}$ & $0.77^{* *}$ & $0.59^{* \neq}$ & $0.56^{\ddagger}$ & $0.54^{\ddagger}$ & $0.53^{\ddagger}$ & $0.54^{\ddagger}$ & $0.54^{\ddagger}$ & $0.55^{\ddagger}$ \\
\hline$\left[\mathrm{Ca}^{2+}\right](\mu \mathrm{m})$ & \pm 0.06 & \pm 0.07 & \pm 0.10 & \pm 0.13 & \pm 0.04 & \pm 0.05 & \pm 0.05 & \pm 0.06 & \pm 0.06 & \pm 0.06 & \pm 0.5 \\
\hline$\%$ change & & $+17.2^{\ddagger}$ & $+29.0^{* *}$ & $+42.3^{* *}$ & +8.0 & $+3.8^{\ddagger}$ & $-0.2^{\ddagger}$ & $-2.2^{\ddagger}$ & -1.8 & -4.0 & -5.0 \\
\hline & & \pm 17.5 & \pm 25.4 & \pm 31.6 & \pm 9.6 & \pm 6.9 & \pm 2.9 & \pm 2.9 & \pm 3.0 & \pm 1.9 & \pm 2.9 \\
\hline$n$ & 6 & & & & & & & & & 5 & 4 \\
\hline
\end{tabular}

LVP, left ventricular developed pressure; TPP, time to peak pressure; $\mathrm{T}_{50 \%} \mathrm{P}$, time to $50 \%$ pressure decline; $\left[\mathrm{Ca}^{2+}\right]_{\mathrm{i}}$, intracellular $\mathrm{Ca}^{2+} ; \%$ change, percent change from preischemic control; $n$, number of observations; ${ }^{*} P<0.05$ versus preischemic control; ${ }^{\ddagger} P<0.05$ compares values before and during perfusion with buffer containing $10^{-8} \mathrm{M}$ nisoldipine. 
$10^{-7} \mathrm{M}$ permitted nearly complete recovery of relaxation following low flow ischemia in rabbits (20). Our results (Table I) regarding the effects of nisoldipine on left ventricular relaxation, are consistent with this report. It should be noted, however, that nisoldipine decreased left ventricular developed pressure, produced a rise in end-diastolic pressure at baseline, and produced further slight changes during reperfusion. We believe that these changes, which were associated with decreased systolic $\left[\mathrm{Ca}^{2+}\right]_{i}$, are consistent with the negative inotropic actions of the drug $(6,15,18)$. Vasodilatation produced by nisoldipine probably accounts for the increase in end-diastolic pressure (21) since end-diastolic $\left[\mathrm{Ca}^{2+}\right]_{\mathrm{i}}$ remained unchanged. However, a drug-induced change in myofilament $\mathrm{Ca}^{2+}$ responsiveness was not ruled out by these experiments.

Effects of nisoldipine on $\left[\mathrm{Ca}^{2+}\right]_{i}$. In recent years, it has become possible to measure changes in cytosolic $\mathrm{Ca}^{2+}$ concentrations of coronary-perfused hearts by three different techniques: (a) ${ }^{19} \mathrm{~F}$ nuclear magnetic resonance (NMR); (b) fluorescent $\mathrm{Ca}^{2+}$ indicators; and $(c)$ aequorin (11). Using ${ }^{19} \mathrm{~F}$ NMR, Marban et al. (22) and Steenbergen et al. (23) have reported increases in $\left[\mathrm{Ca}^{2+}\right]_{\mathrm{i}}$ levels induced by brief periods of ischemia in buffer-perfused hearts. Similar observations were made in studies with the fluorescent $\mathrm{Ca}^{2+}$ indicator Indo-1 by Lee et al. (1) and with the bioluminescent $\mathrm{Ca}^{2+}$ indicator aequorin by $\mathrm{Ki}$ hara et al. (2). Under control preischemic conditions the results of these three different techniques are similar qualitatively $(2$, $3,23,24)$. The extent to which $\left[\mathrm{Ca}^{2+}\right]_{\mathrm{i}}$ rises during ischemia appears to vary somewhat with the indicator technique, the experimental protocol, and the animal species used. All three techniques, however, indicate that the mechanical dysfunction that develops during ischemia is associated with two prominent findings: (a) a marked rise in systolic and diastolic $\left[\mathrm{Ca}^{2+}\right]_{\mathrm{i}} ;(b) \mathrm{a}$ marked decrease in myofilament $\mathrm{Ca}^{2+}$ responsiveness $(2,3)$.

The potential mechanisms explaining the apparent dissociation between changes in $\left[\mathrm{Ca}^{2+}\right]_{\mathrm{i}}$ and mechanical function have recently been summarized by Steenbergen et al. (7). In brief, the major changes accounting for the profound decrease in myofilament $\mathrm{Ca}^{2+}$ sensitivity appear to be increases in intracellular phosphate and hydrogenation. The former change arises as a result of ATP breakdown during ischemia; the latter as the heart switches from aerobic to anaerobic metabolism. These conclusions are supported in the present series of experiments by the rise in lactate levels which occurred during ischemia. The rise in systolic and diastolic $\left[\mathrm{Ca}^{2+}\right]_{\mathrm{i}}$ during ischemia may also be caused by the developing acidosis which drives the sodium-proton exchanger of the sarcolemma to bring $\mathrm{Na}^{+}$into the cell in exchange for hydrogen ion extrusion. As a result of the increase in intracellular $\mathrm{Na}^{+}$, transsarcolemmal sodiumcalcium exchange is stimulated, resulting in a marked $\left[\mathrm{Ca}^{2+}\right]_{\mathrm{i}}$ rise. In addition, abnormalities of sarcoplasmic reticular and/ or mitochondrial $\mathrm{Ca}^{2+}$ release and uptake may play some role, but appear to be relatively less important $(1,7)$.

Lee et al. (1) indicated that verapamil $(0.25 \mu \mathrm{M})$ decreased diastolic and systolic $\left[\mathrm{Ca}^{2+}\right]_{\mathrm{i}}$ during ischemia in rabbit hearts loaded with the fluorescent $\mathrm{Ca}^{2+}$ indicator Indo-1. Endothelial cells, however, may have contributed a portion of the recorded signal (25). In a study with ${ }^{19} \mathrm{~F}$ NMR, Steenbergen et al. (7) reported that diltiazem $(0.9 \mu \mathrm{M})$ attenuated the ischemia-induced rise in $\left[\mathrm{Ca}^{2+}\right]_{i}$ in hearts loaded with 5F-BAPTA. The results of the present study lead to the same conclusion by a different experimental approach with regard to nisoldipine, the second generation calcium antagonist.
Of interest, however, our results during reperfusion in both control and nisoldipine experiments showed triphasic LVEDP responses, which were different from the behavior of diastolic $\left[\mathrm{Ca}^{2+}\right]_{\mathrm{i}}$ (rise followed by a slight decline, followed by a second rise at a time when diastolic $\left[\mathrm{Ca}^{2+}\right]_{i}$ was gradually falling). Similar results have been reported during reperfusion by other investigators $(1,13)$. This apparent dissociation between diastolic $\left[\mathrm{Ca}^{2+}\right]_{\mathrm{i}}$ and tension may be related to abnormal calcium modulation, as suggested by Lee et al. (1). Moreover, abrupt reflow could produce a transient increase in vascular turgor (i.e., "garden-hose" effect), resulting in a slightly elevated LVEDP. Alternatively, metabolic alterations during reperfusion could be producing changes in myofilament $\mathrm{Ca}^{2+}$ responsiveness that contribute to the change above (23).

In summary, the results of the present study show that the calcium antagonist nisoldipine reduces the ischemia-induced rise in systolic and diastolic $\left[\mathrm{Ca}^{2+}\right]_{i}$, and lessens the corresponding decrease in contractile function. These beneficial effects probably occur through a combination of this drug's direct actions on the voltage-dependent sarcolemmal $\mathrm{Ca}^{2+}$ channels and the consequent energy sparing effects resulting from diminution of contractility. Although not directly tested in the present series of experiments, we suggest that these actions may be of therapeutic use in man.

\section{Acknowledgments}

We would like to express appreciation to Mr. Jason Kravitz for his secretarial assistance, and Dr. William P. Hood, Jr. for his helpful suggestions.

This study was supported in part by U. S. Public Health grants DA-05171 and HL-31117. Dr. James P. Morgan received a Research Career Development Award HL-01611 from the National Heart, Lung, and Blood Institute; and Dr. Ivo Amende received support from the Ministry of Science and Culture, Lower Saxony, Germany.

\section{References}

1. Lee, H. C., R. Mohabir, N. Smith, M. R. Franz, and W. T. Clusin. 1988. Effects of ischemia on calcium-dependent fluorescence transients in rabbit hearts containing indo 1: correlation with monophasic action potentials and contraction. Circulation. 78:1047-1059.

2. Kihara, Y., W. Grossman, and J. P. Morgan. 1989. Direct measurement of changes in intracellular calcium transients during hypoxia, ischemia, and reperfusion of the intact mammalian heart. Circ. Res. 65:1029-1044.

3. Kusuoka, H., Y. Koretsune, V. P. Chacko, M. L. Weisfeldt, and E. Marban. 1990. Excitation-contraction coupling in postischemic myocardium. Does failure of activator $\mathrm{Ca}^{2+}$ transients underlie stunning? Circ. Res. 66:1268-1276.

4. Clark, R. E., I. Y. Christlieb, P. D. Henry, A. E. Tischer, J. D. Nora, J. R. Williamson, and B. E. Sobel. 1979. Nifedipine: a myocardial protective agent. Am. J. Cardiol. 44:825-831.

5. Nayler, W. G., R. Ferrari, and A. Williams. 1980. Protective effect of pretreatment with verapamil, nifedipine and propranolol on mitochondrial function in the ischemic and reperfused myocardium. Am. J. Cardiol. 46:242-248.

6. Watts, J. A., L. J. Maiorano, and P. C. Maiorano. 1985. Protection by verapamil of globally ischemic rat hearts: energy preservation, a partial explanation. J. Mol. Cell Cardiol. 17:797-804.

7. Steenbergen, C., E. Murphy, J. A. Watts, and R. E. London. 1990. Correlation between cytosolic free calcium, contracture, ATP, and irreversible ischemic injury in perfused rat heart. Circ. Res. 66:135-146.

8. Blinks, J. R., W. G. Wier, P. Hess, and F. G. Prendergast. 1982. Measurement of $\mathrm{Ca}^{2+}$ concentrations in living cells. Prog. Biophys. Mol. Biol. 40:1-114.

9. Watts, J. A., L. J. Maiorano, and P. C. Maiorano. 1986. Comparison of the protective effects of verapamil, diltiazem, nifedipine, and buffer containing low calcium upon global myocardial ischemic injury. J. Mol. Cell. Cardiol. 18:255263. 
10. Kihara, Y., and J. P. Morgan. 1991. Intracellular calcium and ventricular fibrillation: Studies in the aequorin-loaded isovolumic ferret heart. Circ. Res. 68:1378-1389.

11. Blinks, J. R. 1986. Intracellular $\left[\mathrm{Ca}^{2+}\right]$ measurements. In The Heart and Cardiovascular System: Scientific Foundations. H. A. Fozzard, E. Haber, and R. B. Jennings, editors. Raven Press, New York. 671-701.

12. Allen, D. G., and C. H. Orchard. 1983. Intracellular calcium concentration during hypoxia and metabolic inhibition in mammalian ventricular muscle. J. Physiol. Lond. 339:107-122.

13. Apstein, C. S., L. Deckelbaum, L. Hagopian, and W. B. Hood, Jr. 1978. Acute cardiac ischemia and reperfusion: contractility, relaxation, and glycolysis Am. J. Physiol. 4:H637-648.

14. Weisfeldt, M. L., P. Armstrong, H. E. Scully, C. A. Sanders, and W. M. Daggett. 1974. Incomplete relaxation between beats after myocardial hypoxia and ischemia. J. Clin. Invest. 53:1626-1636.

15. Taira, N., and K. Takahashi. 1987. Cardiovascular profile of nisoldipine as compared to nifedipine in dogs. In Nisoldipine 1987. P. G. Hugenholtz and J. Meyer, editors. Springer-Verlag, Berlin/Heidelberg/New York/London/Paris/ Tokyo. 131-143.

16. de Jong, J. W., T. Huizer, and J. G. P. Tijssen. 1984. Energy conservation by nisoldipine in the ischemic heart. Br. J. Pharmacol. 83:943-949.

17. de Jong, J. W., and T. Huizer. 1985. Reduced glycosis by nisoldipine treatment of ischemic heart. J. Cardiovasc. Pharmacol. 7:497-500.

18. Watts, J. A., J. P. Whipple, and A. A. Hatley. 1987. A low concentration of nisoldipine reduces ischemic heart injury: enhanced reflow and recovery of con- tractile function without energy preservation during ischemia. $\mathrm{Mol}$. Cell. Cardiol. 19:809-817.

19. Katz, A. M. 1986. Potential deleterious effects of inotropic agents in the therapy of chronic heart failure. Circulation. 73(Suppl. III):III-184-188.

20. Henry, P. D., R. Shuchleib, J. Davie, E. S. Weiss, and B. E. Sobel. 1977. Myocardial contracture and accumulation of mitochondrial calcium in ischemic rabbit heart. Am. J. Physiol. 233:H677-684.

21. Amende, I., R. Simon, W. P. Hood, R. Hetzer, and P. R. Lichtlen. 1983. Intracoronary nifedipine in human beings: magnitude and time course of changes in left ventricular contraction/relaxation and coronary sinus blood flow. J. Am. Coll. Cardiol. 2:1141-1145.

22. Marban, E., M. Kitakaze, H. Kusuoka, J. K. Porterfield, D. T. Yue, and V. P. Chacko. 1987. Intracellular free calcium concentration measured with ${ }^{19} \mathrm{~F}$ NMR spectroscopy in intact ferret hearts. Proc. Natl. Acad. Sci. USA. 84:60056009.

23. Steenbergen, C., E. Murphy, L. Levy, and R. E. London. 1987. Elevation in cytosolic free calcium concentration early in myocardial ischemia in perfused rat heart. Circ. Res. 60:700-707.

24. Mohabir, R., R. W. Kurz, and W. T. Clusin. 1990. Calibration of cytosolic calcium transients during global ischemia in rabbit heart. Circulation. 82(Suppl. III):570a. (Abstr.)

25. Lorell, B. H., C. S. Apstein, M. J. Cunningham, F. J. Schoen, E. O. Weinberg G. A. Peeters, and W. H. Barry. 1990. Contribution of endothelial cells to calcium-dependent fluorescence transients in rabbit hearts loaded with Indo 1. Circ. Res. 67:415-425 